\title{
Die stand van die Gereformeerde kerkreg
}

C J Botha

\begin{abstract}
The stance of Reformed church polity

The author deals with the resistance against the study of church polity and stresses its necessity. He sketches the development in Protestant church polity, and then investigates the fact that the confessions function as the paradigm for a particular church. The problem with the reformed confessions is that they are based on sixteenth century exegesis. Consequently there is a growing rift between church polity and the Biblical disciplines. He argues for a debate on the issue of the reformulation of the reformed confessions, and that Mt 28:18-20 be the Scriptural "sitz im leben " of church polity and not 1 Cor 14:40.
\end{abstract}

Die grondigste beswaar wat nog ooit teen die vak kerkreg ingebring is, het gekom van die Duitse teoloog, Rudolph Söhm (1841-1917). Hy het sy beswaar só geformuleer: "Das Wesen der Kirche und das Wesen des Rechtes stehen miteinander in Widerspruch... Die Wesen der Kirche ist geistlich, das Wesen des Rechtes is weltlich"1. Ek kan nie nou met Söhm in debat tree nie, en wil slegs twee opmerkings oor sy stelling maak: Eerstens moet ons Söhm se kritiek vanuit die konteks van sy teologie probeer verstaan. Hy was 'n Lutheraan, en het gedink vanuit die Lutherse kerkbegrip. Luther het geleer dat die ware kerk die onsigbare congregatio fidelium is, dit wil sè, die ware weergebore volgelinge van Jesus Christus. Hulle het eintlik nie wette nodig nie, want hulle ken die stem van die Goeie Herder en hulle volg Hom. Teenoor hierdie Onsigbare Kerk is daar hierdie sigbare byeenkoms rondom Woord en sakramente, waar daar gelowiges, skyngelowiges, soekers en ongelowiges is. Hierdie sigbare kerk is by Luther weinig meer as 'n preekinstituut wat God gebruik om sy ware gelowiges te red, te voed en te bewaar deur sy Woord en Gees. In die lig van sy Twee-Rykeleer is dit dan die plig van die Christelike staat om toesig te hou oor die wel en weë van die sigbare kerk. Dit is duidelik dat Luther hom nog nie kon losmaak van die Corpus-Christianum-persepsie wat die Middeleeue oorheers het nie.

My tweede opmerking is 'n aanhaling uit een van Söhm se latere werke: "Nogtans het enige sigbare gemeenskap van mense 'n bepaalde ordening nodig, en hierdie absolute noodsaaklikheid het 'n kerkreg tot stand laat kom. As gevolg hiervan het die Oer-Christendom 'n kerkreg na vore gebring met die veronderstelling dat dit vir die hele kerk van Christus sou geld, dit wil sê 'n katolieke kerkreg. 'n Sigbare menslike gemeenskap wat wil saamleef kan nie sonder so 'n ordening wees nie. Dit het behoefte aan so 'n algemeen-geldige orde wat iewers in die verlede tot stand gekom het en ook die huidige situasie beheer"2.

Lait ons nou probeer om helderheid oor hierdie sogenaamde noodsaaklike euwel te kry. Agter elke kerkregstelsel - en daar is ses onderskeibare stelsels is die grondgedagte dat Christus die Koning van die Kerk is. Al dié stelsels glo op een of ander inanier dat die Heilige Gees en die Bybel 'n belangrike rol in hierdie regering van Christus speel. 
Die Protestantisme, en daarom ook die Gereformeerde kerkreg, het ontstaan uit 'n protes teen die Roomse of Papale kerkregeringstelsel. Volgens Rome sou Christus Petrus aangestel het as sy plaasbekleder op aarde - hulle beroep hulle op Matteus 16:18,19: "Jy is Petrus, en op hierdie rots sal Ek my kerk bou, en die magte van die doderyk sal dit nie oorweidig nie. Ek sal aan jou die sleutels van die koninkryk van die hemel gee, en wat jy op die aarde toesluit sal in die hemel toegesluit bly, en wat jy op die aarde oopsluit sal in die hemel oopgesluit bly". Die rede vir die protes van die Reformatore was dat Rome Christus so laat opgaan in die biskop van Rome "dat daar nie sprake kan wees van twee hoofde vir die kerk, Christus en die pous nie, maar slegs een: "Christus-in-gemeenskap-met-sy-plaasvervanger" 3 . Christus en die biskop van Rome word eenvoudig in 'n onverbreekbare verbondenheid gesien, waarby laasgenoemde Christus sonder meer verteenwoordig. "Deur hierdie vereenselwiging van Christus en die pous is alle heerskappy van die pous ook vanselfsprekend gelyk aan Christus. Christus regeer wel, maar Hy doen dit deur die pous"4.

Luther se protes het 'n uitdruklike kerkregtelike kleur ontvang toe hy by die Elstorpoort nie net die bul Exsurge Domine verbrand het nie, maar ook die hele bundel kanonieke reg. 'n Mens moet egter versigtig wees om nie te veel in hierdie optrede te lees nie. Dit was nie soseer 'n protes teen kerkreg as sodanig nie, maar eerder teen die hic et nunc-kerkreg. Die feit dat hy self nie 'n kerkreg opgestel het nie, moet ook nie vertolk word asof hy nie 'n plek vir kerkrcg gehad het nie, maar sy verbystering met die ontdekking dat God die sondaar slegs op grond van sy genade regverdig. In die lig van hierdie Goddelike regspraak is die kerk, die pous en sy hele hiërargie slegs menslike regsordeninge. Plomp oordeel reg as hy die hart van Luther se kerkregtelike denke in die volgende uitspraak aantoon: "As die evangelie reg verkondig word en die sakramente reg bedien word, sal die nuwe kerklike ordening spontaan en suiwer daaruit voortvloei"5.

Toe dit alles nie so mooi in die praktyk uitgewerk het nie, het Luther 'n noodkerkreg laat funksioneer. Dit toon dat Luther die kerkreg ondergeskik gestel het aan die heilsboodskap. Die heilsboodskap was vir hom die lus divinum en om dit tot 'n kerkreg te transformeer, het heeltemal buite sy denkveld geval. Die kerkreg was vir hom adiaphoron, en toe die gelowiges deur die prediking van die evangelie rondom hom begin vergader het, en duidelik een of ander ordening nodig gehad het, het hy as noodmaatreël die landvorste gevra om 'n gemeenteordening te skep en te handhaaf. Ook dit moet gesien word binne die laat-middeleeuse visie van die landsvors as imperator in territoria sua.

Hoe heeltemal anders het die juris en leke-teoloog Johannes Calvyn die kerkreg nie gesien nie. Sy grondgedagte was dat die majesteit van God die grondslag van alle regsordening is. God bring samehang in hierdie aardse bestaan. Hy het elke gemeenskapsordening geskep, ook die kerk. Daarom het Calvyn hom sy hele lewe lank met die regte ordening van die kerk besig gehou. In sy reaksie op die Roomse hiërargie het Calvyn 'n kerkorde ontwikkel wat van onder af, van die plaaslike gemeentes af, gegroei het. Hy vermy Luther se aksent op die onsigbaarheid van die kerk deur elke gemeente te sien as 'n sigbare gestalte van die kerk. Die uitgangspunt van sy kerkreg is die goedgeorganiseerde gemeente. Dit kom baie duidelik in sy Ordonnances Ecclesiastiques van 1541 na vore. Die grondbeginsel van sy kerkreg is die outonomie van die plaaslike gemeente of kerk, maar tog balanseer hy dit baie sorgvuldig met die ander grondbeginsel dat al die gemeentes saam ook 
weer een is. Hierdie beginsel word deur 'n deel van die gereformeerde kerkreg onderspeel. Die gemeente wat hy volgens sy vermeende oer-Christelike kerkorde "hervorm" het, is gedien deur vier ampte. Dit is debateerbaar of Calvyn se kerkorde werklik die algemene priesterskap van die gelowiges tot sy reg laat kom het, en of die gewone lidmaat nie tog maar op die agtergrond beland het nie. Dit sou gestel kon word dat die Independente met hulle aksent op die gemeentevergadering as die hoogste gesag, en die ampte wat in wese amptenare van die gemeente is, 'n (dubieuse) poging is om die algemene amp tot sy reg te laat kom.

Calvyn het geglo dat die kerk (=gemeente) 'n skeppingswerk van God is. Hy stuur sy Woord by monde van menslike dienaars die wêreld in. Hierdie herders is deur God self innerlik (deur sy Woord en Gees) geroep om sy Woord te gaan verkondig en dit word later bevestig deur die kerklike ordening of beroep. Oral waar die Woord suiwer gepreek word en die sakramente volgens die instelling van Christus korrek bedien word, sal Christus sy gelowiges bymekaar maak, en in hierdie congregatio word die kerk van Christus sigbaar. Dit lyk of Calvyn die klem laat val het op 'n dinamiese heilsgebeure, en nie op 'n organisasie nie. Maar as Calvyn met die kerklike tug probeer om dié sigbare gestalte van die kerk so na as moontlik te laat ooreenstem met die onsigbare gestalte, naamlik al die ware -gelowiges, dit wil sê die ware kerk waarvan Artikel 27 van die NGB praat, is daar 'n baie belangrike spanning tussen hom en Luther. Luther het enige poging om hierdie sigbare gestalte van die kerk gelyk te stel aan die onsigbare kerk, wat net vir God sigbaar is, as Schwärmerei of kettery afgewys.

Omdat die gemeente 'n gemeenskap van mense is wat met mekaar saamlewe, moet daar in die kerk 'n ordelike lewenspatroon sigbaar word - die vrug van die herskeppende werk van die Heilige Gees. Hierdie orde noodsaak dat daar wette in die kerk moet wees. Hiermee neem hy op twee fronte standpunt in. Hy verwerp enersyds die aanspraak van Rome dat die kanonieke reg heilsnoodsaaklik is, maar andersyds verwerp hy ook die standpunt van die Anabaptiste dat daar geen wette in die kerk of in die staat mag wees nie en dat ons slegs moet lewe volgens die voorskrifte van die Bybel6.

Calvyn se uiteensetting van beginsels vir so 'n kerkordening word in die Institusie IV.10-13 aangetref. Sy locus classicus vir 'n kerkorde is I Korintiërs 14:40: "Alles moet egter gepas (decenter) en ordelik (secundum ordinem) geskied". Hieruit maak Calvyn dan die afleiding dat daar eintlik twee soorte van kerklike wette is. Die eerste het betrekking op die eintlike orde, dit wil sê is kerkordelik in die ware sin van die woord. Die tweede het te doene met die decorum in die kerk, en is dus meer liturgies van aard.

Die verduideliking van Plomp ${ }^{7}$ in hierdie verband is van die allergrootste belang: Calvyn stel dit dat die menslike insettinge wat ons goedkeuring verdien, dié is wat aan die Skrif ontleen is (ex Scriptura desumptae) en daarom geheel en al goddelik is (prorsus divinae). Plomp erken dat dit 'n krasse uitspraak is om te sê dat humanae constitutiones geheel en al goddelik is. Maar hy ontken dat Calvyn daarmee bedoel het dat mens uit die Bybel, en dan by name uit die Nuwe Testament 'n onveranderlike kerkregstelsel kan opbou, wat dan kan geld as iure divino. Hy aanvaar dat Calvyn in die opstel van sy kerkorde Bybelse aanwysings (nous est monstre par lescripture) as buitengewoon belangrike data hanteer het, maar dat hy daarby ook die lordre de lesglise ancienne (die vorme van die vroeë kerk) ernstig in aanmerking geneem het. Die volgende stelling van Plomp sal ernstig geneem moet 
word: "Aangezien Hij (onze enige Meester) echter in de uiterlijke orde en de ceremoniën (in externa disciplina et ceremoniis) niet alles in details heeft willen voorschrijven wat wij te volgen hebben, omdat Hij voorzag dat dit van de tijdsomstandigheden (a temporum conditione) afhankelijk zou zijn en Hij niet van oordeel was dat een vorm voor alle eeuwen passend zou zijn, moeten wij de toevlucht nemen tot de 'generales regulas' die Hij gegeven heeft, opdat daarnaar alles beoordeeld wordt wat de 'neccessitas Ecclesia' ter zake van de 'ordo' en het 'decorum' aan voorschriften zal vereisen"8.

Hieruit lei Plomp af dat Calvyn daarvan oortuig was dat kerklike wette nie alleen van tyd tot tyd verander mag word nie, maar moet verander word. Die kerkorde is geen perpetua lex wat vir alle tye en volke geld nie. Calvyn gee toe dat mens non temere, nec subinde, nec levibus de causis tot vernuwing mag oorgaan nie, want dit sou die kerk kon skade aandoen, maar wanneer die Ecclesiae aedificatio et Ecclesiae utilitas dit vereis, kan en moet daar vernuwing kom. Of hierdie beginsel in die Gereformeerde kerkreg nagekom is, wil ek bevraagteken in die lig van die status van die Dordtse Kerkorde.

Die Gereformeerde Ortodoksie het Calvyn se teologie, veral soos dit in die Institusie verwoord is, in drie belydenisse vasgele en hierdie belydenisskrifte is op die Sinode van Dordt (1618-19) as die Drie Formuliere van Enigheid aangedui. Op dieselfde sinode is die kerkorde goedgekeur wat ons vandag ken as die Dordtse Kerkorde, wat in die gereformeerde kerkreg vandag nog as normatief vir die kerkreg hanteer word.

Toe ek in 1979 as opgaaf gehad het om die gereformeerde kerkreg vir die toekomstige predikante van die Nederduitse Gereformeerde Sendingkerk te doseer, was ek oortuig daarvan dat die Dordtse Kerkorde die suiwerste vormgewing van die kerke van gereformeerde belydenis geformuleer het. Ek het daarom die tendens om die studente die kerkwette uit die hoof te leer, as positivisties verwerp, en my daarop toegelê om elke artikel van die Dordtse Kerkorde teologies te bestudeer en sodoende beklemtoon dat kerkreg 'n teologiese dissipline is. Dit was in die tyd wat my oë begin oopgaan het vir sekere probleme in die gereformeerde kerkreg. Hierin is ek gehelp deur studente wat werklik in die teologie van die kerkreg begin belangstel het, en teologies-krities met my in gesprek getree het. Die vrae was wel soms gebore uit die dampkring van die bevrydingsteologie, maar talle van hulle kritiese vrae het vir my gegrond voorgekom. As ek dié kritiese vrae kortliks kan saamvat, het dit op die volgende neergekom: Hulle het my daarop gewys dat soveel van die kerkreg vir hulle irrelevant was omdat dit nie die situasie waarin die Nederduitse Gereformeerde Sendingkerk vasgevang is, aanspreek nie. Hulle het my daarop gewys dat die Dordtse Kerkorde 'n sewentiende-eeuse Nederlandse situasie aanspreek, en dat dit gebaseer is op 'n sewentiende eeuse belydenis wat antwoorde gee op teologiese probleme van daardie tyd en plek. Maar hulle vind dit erg moeilik om die Drie Formuliere van Enigheid as 'n gloeiende belydenis van hulle eie hart te onderskryf. Hulle erken die groot algemene waarhede wat daarin vervat is, maar die aktuele teologiese debatpunte van ons dag word nie daarin aangespreek nie, en dus vind hulle ook die Dordtse Kerkorde as 'n vreemde ordening wat beswaarlik kan slaag om die Nederduitse Gereformeerde Sendingkerk dinamies te orden.

In my leeswerk het ek ook uit ander hoeke begin vraagtekens opvang. Ek noem enkele voorbeelde. In 1985 het Spoelstra 'n baie gedagteprikkelende artikel 
gepubliseer waarin hy die vraag gestel het of die gereformeerde kerkbegrip nie in strukture gestol het nie. Hy het my opnuut bewus gemaak van die dinamiese karakter van die kerk soos dit in die begrip ekklesia tot uitdrukking kom9. Studie oor die Duitse kerkstryd het onder meer twee belangrike kerkregtelike geskrifte van Karl Barth onder my aandag gebring, te wete Rechtfertigung und Recht (1938) en Christengemeinde und Burgergemeinde (1946). Barth het geen twyfel daaroor gehad dat daar ' $n$ vorm van kerkregering moet wees wat reg en orde in die kerk kan handhaaf nie. Op 'n unieke manier het hy egter die feit beklemtoon dat die kerk nie homself regeer nie, maar dat Jesus Christus die kerk regeer. Alle kerkreg kom dus neer op 'n luister na die stem van Jesus. Hy het die hele kerkreg onder drie begrippe georden: diensreg, liturgiese reg en lewende reg. Hierdie diens in die kerk is basies die taak van die algemene priesterskap van alle gelowiges, en hulle kan dit hoogstens aan bepaalde "ampsdraers" delegeer, want na sy aard is die kerk 'n Christokratiese broederskap. Kerkreg moet dus altyd 'n dinamiese, bewegende reg wees, wat deur die Heilige Gees in beweging gehou word. Laasgenoemde stelling het my opgeval veral omdat studies oor die vakgebied van die gereformeerde kerkreg weinig meer gedoen het as om die bekende kerkregtelike beginsels opnuut te beklemtoon. Dit is 'n vraag of doktorale studente werklik 'n nuwe bydrae tot die wetenskap kan maak. 'n Mens kry die indruk dat die gereformeerde kerkeg soos 'n uitgewerkte mynskag is; 'n mens kan die stawe ontginde goud bewonder, maar daar is nie nuwe goud uit te haal nie.

Oor die kerkreg in Lutherse kringe kan die volgende opmerking gemaak word: "'n Mens kry die indruk dat die kerkreg in geen ander kring so aktief beworstel word as in die Lutherse wêreld nie. Sou dit kon wees dat Luther se belangrikste bydrae tot die Lutherse kerkreg juis was dat hy nie 'n 'model'-kerkreg geformuleer het wat vir sy volgelinge onaantasbaar sou gebly het nie, ten spyte van geweldige ontwikkcling op die gebied van die Bybeleksegese? Sodoende het die Lutherse kerkreg, net soos die Lutherse kerkbegrip, nie gestol nie. So bly dit 'n Kirchenverfassung in via net soos wat die kerk ook Ecclesia in via moet bly"10. Dit gaan egter nie net in die Lutherse deel van die kerkreg lewendig daaraan toe nie, maar in die hele Evangeliese kerkreg, wat ook die Duitse gereformeerdes insluit.

Coertzen het ook op die Duitse kerkreg gekonsentreer en aangetoon dat die Duitse kerkstryd die Duitse kerkregtelikes, soos E Wolf en andere gedwing het om 'n paradigmaverandering te doen. Hy het aangetoon hoe belangrik ' $n$ paradigma vir die beoefening van kerkreg is deur daarop te wys dat die paradigma van die gereformeerde kerkreg dit nie eintlik toelaat dat vroue tot die amp toegelaat kan word nie. Hy het sy argument soos volg afgesluit: "Progression in church law and church government needs continous work on points of departure such as the Kingdom of God, the church as a making of the triune God, Jesus Christ as the head of the church, Christ's government of the church through his Word, Spirit and the services which tle has given in the church and the aims of church law and church government. In this way only, much needed answers can be given to burning issues and can true progress be made" 11 .

Coertzen het egter nie diep genoeg gedelf na die eintlike paradigma van die gereformeerde kerkreg, naamlik die belydenisskrifte nie. Na my oordeel is die belydenisskrifte 'n bepaalde tradisie hoe die Skrif uitgelê moet word. Solank hierdie Skrifuitleg hindend is vir dic kerkreg, kan daar nic voortheweeg word in die kerkreg nie, omdat ons basies gebind bly aan die eksegese van die sestiende eeu. 
Tussen ons en die Sinode van Dordt lê die Aufklärung, 'n geestesbeweging wat die mensdom se geskiedenis radikaal verander het.

Die Christelike teologie het op allerlei wyses probeer om 'n Bybelse antwoord op die denkwêreld na die Aufklänung te gee, maar dit is wesenlik deur die gereformeerde teologie as "modernisme" afgewys. Ten spyte hiervan wil dit tog voorkom of die histories-kritiese metode van eksegese oor die algemeen deur die Bybelwetenskappe aanvaar is, al sou dit in getemperde vorm wees. Dit het 'n kloof tussen die Bybelwetenskappe en die kerkreg gebring. Die kerkreg steun nie meer op die eksegese van Ou-Testamentici en Nuwe-Testamentici nie. Die interessante is dat die Evangelische Kirchenrecht nie hierdie kloof het nie. As ons werklik gereformeerde kerkreg wil beoefen, sal ons erns moet neem om weer te werk met die Bybelstof wat die Bybelwetenskappe vir ons voorsien.

'n Herbesinning oor die rol van ons belydenisskrifte is dus noodsaaklik. Tans is daar ' $n$ interessante debat hieroor met belangrike bydraes wat gelewer is deur groot teoloë soos onder meer K Barth, Das Bekenntnis der Reformation und unser Bekennen (1935); $\mathrm{H}$ Gollwitzer, Die bedeutung des Bekenntnisses für die Kirche (1962); A A van Ruler, Hoe functionneer de belijdenis (1954); H Volten, Rondom het belijden der Kerk (1962); H M Kuitert, Moeten we een nieuwe belijdenis hebben? (1972); C Augustijn, Kerk en belijdenis (1971) en J van Genderen, Confessie en theologie (1975). Hierdie debat moet ook in ons land deurdringend en eerlik gevoer word.

In Nederland het die Nederlandse Hervormde Kerk, die Gereformeerde Kerke in Nederland en die Lutherse Kerk in Nederland ernstige eenheidsgesprekke wat gevoer word onder die leuse Samen op weg. Hulle werk onder meer aan 'n nuwe kerkorde wat vir al drie die betrokke kerke aanvaarbaar sal wees. Om dit te kon doen moes hulle saam ' $n$ intense studie doen van die teologie van die kerkreg. Hierdie rapporte behoort boeiende studiemateriaal vir die kerkreg ook hier te lande te wees. Ek kan net vertrou dat ons kerkregtelikes so toegerus sal wees deur ons kennis van die teologie van die kerkreg dat ons in staat sal wees om so 'n nuwe kerkorde te kan opstel wat met al die kennis en ervaring van twintig eeue 'n werklik Bybels-teologiese kerkordening sal wees en wat niks afbreuk doen aan die beginsels in die Dordtse Kerkorde vervat nie, maar daarmee 'n paar treë verder sal vorder. Todt ${ }^{12}$ bied Matteus 28:18-20 "Aan My is alle mag gegee in die hemel en op aarde. Gaan dan na al die nasies toe en maak die mense my dissipels: doop hulle in die Naam van die Vader en die Seun en die Heilige Gees, en leer hulle om alles te onderhou wat Ek julle beveel het. En onthou: Ek is by julle al die dae tot die voleinding van die wêreld" aan as locus classicus vir die kerkorde, 'n teks wat veel meer gepas is as I Korintiërs 14:40. Sou die vers nie as grondslag vir 'n nuutgeformuleerde gereformeerde kerkreg kon gebruik word nie?

\section{NOTAS:}

1 R Söhm, Kirchenrecht I, Leipzig 1892, 439 en 657.

2 R Söhm, Das altkatholische Kirchenrecht und das dekret Gratians, Leipzig $1918,3,4$.

W D Jonker, Om die regering van Christus in sy kerk, Pretoria 1965, 5. 
$4 \quad$ W D Jonker, $a w, 1965,5$.

5 J Plomp, Beginselen van Reformatorische kerkrecht, Kampen 1967, 10.

6 J Plomp, $a w, 1967,14$.

$7 \quad$ J Plomp, $a w, 1967,14$ en 15.

$8 \quad J$ Plomp, $a w, 1967,16$.

9 B Spoelstra, "Het ons kerkbegrip in strukture gestol?" Hervormde Teologiese Studies Vol 45(1) 1985, 94-110.

10 C J Botha, "Die grondbeginsels van Luther se kerkreg", Studia Historiae Ecclesiasticae vol XV/1 1989, 1-17.

11 P J Coertzen, "The role of paradigms in church law and the government of the church", in: J Mouton, A G van Aarde en W S Vorster (ed) Paradigms and progress in theology, Pretoria 1988, 360.

12 H E Todt, "Wege zur identifizierung und Auslegung von Biblischen Recht" in: H Schliach (red), Studien zu Kirchenrecht und Theologie, Heidelberg 1987. 93. 